\title{
Labyrinthe
}

$40 \mid 2013$

Comme les abeilles

\section{Maeterlinck et les abeilles}

\author{
Lætitia Mouze
}

\section{OpenEdition}

Journals

Édition électronique

URL : http://journals.openedition.org/labyrinthe/4322

DOI : $10.4000 /$ labyrinthe.4322

ISSN : 1950-6031

Éditeur

Hermann

Édition imprimée

Date de publication : 1 mars 2013

Pagination : 99-102

ISBN : 9782705688400

\section{Référence électronique}

Lætitia Mouze, « Maeterlinck et les abeilles », Labyrinthe [En ligne], 40 | 2013, mis en ligne le 01 mars

2015, consulté le 01 mai 2019. URL : http://journals.openedition.org/labyrinthe/4322 ; DOI : 10.4000/ labyrinthe.4322

Propriété intellectuelle 


\section{Maeterlinck et les abeilles}

Lætitia Mouze

Maeterlinck (1862-1949), natif de Gand et mort à Nice, a commencé comme poète, publiant dans des revues dans les années 1880. Son recueil Serres chaudes est paru en 1889. Dans les 1880-1890, il découvre l'idéalisme allemand - Hegel, Schopenhauer -, le mystique flamand Jean de Ruisbroek (XIV ${ }^{\mathrm{e}}$ siècle), qu'il a traduit, et Novalis. Puis, il écrit quelques pièces : la première est La Princesse Malein (1890). D'autres pièces ont suivi: Pelléas et Mélisande, la plus connue, la féérie de 1908 L'Oiseau bleu, qui est extrêmement célèbre, et d'autres encore comme L'Intruse, Les Aveugles, etc. Le troisième volet de son œuvre (après la poésie et le théâtre), ce sont les essais: Le Trésor des humbles, La Sagesse et la destinée ou encore Le Double Jardin. Et là-dedans s'intercale en 1901 La Vie des abeilles, ouvrage de philosophie de la nature, ouvrage scientifique. Maeterlinck a lui-même une pratique d'apiculteur. Un peu plus tard viennent L'Intelligence des fleurs (en 1907) et beaucoup plus tard La Vie des termites et La Vie des fourmis.

Le lien de tout cela, de cette œuvre éclatée, c'est le symbolisme. Du symbolisme, il n'y a pas, dit-on, de définition unique. Une définition en a été donnée, que cite Bertrand Delvaille dans La Poésie symboliste (1971). Cette définition, c'est la réponse de Mallarmé à une enquête littéraire, à la fin du XIX ${ }^{\mathrm{e}}$ siècle:

La contemplation des objets, l'image s'envolant des rêveries suscitées par eux, sont le chant: les Parnassiens, eux, prennent la chose entièrement et la montrent: par là ils manquent de mystère; ils retirent aux esprits cette joie délicieuse de croire qu'ils créent. Nommer un objet, c'est supprimer les trois quarts de la jouissance du poème qui est faite de deviner peu à peu: le suggérer, voilà le rêve. C'est le parfait usage de ce mystère qui constitue le symbole: évoquer petit à petit un objet pour montrer un état d'âme, ou, inversement, choisir un objet et en dégager un état d'âme, par une série de déchiffrements. 


\section{Labyrinthe, $n^{\circ} 40$}

Cette définition par Mallarmé convient assez bien au symbolisme de Maeterlinck qui, pour Paul Gorceix, spécialiste de Maeterlinck, s'enracine dans la croyance de ce dernier en l'unité de toutes choses ${ }^{1}$. S'il y a symbolisme, c'est d'abord non pas pour des raisons formelles ou stylistiques, mais pour des raisons de fond, de conception de la nature.

La Vie des abeilles prend place dans cet œuvre de Maeterlinck poésie, théâtre, essais -, loin de se séparer de cet ensemble. Elle n'est pas un hapax, une parenthèse dans l'ensemble: elle est insérée à l'intérieur et elle participe d'un projet unique.

1. Dans sa préface au recueil Serres chaudes (Paris, Gallimard, 1983), Paul Gorceix cite une phrase de Maeterlinck dans Le Sablier: «Matière, esprit, c'est de l'eau bleue ou de l'eau rouge, la couleur diffère, mais c'est toujours de l'eau. » 


\title{
L’amour piqué par une abeille
}

\author{
Le petit enfant Amour \\ Cueillait des fleurs à l'entour \\ D'une ruche, où les avettes
}

Font leurs petites logettes.

Comme il les allait cueillant, Une avette sommeillant

Dans le fond d'une fleurette

Lui piqua la main douillette.

Sitôt que piqué se vit,

"Ah, je suis perdu! " ce dit,

Et, s'en courant vers sa mère,

Lui montra sa plaie amère ;

" Ma mère, voyez ma main,

Ce disait Amour, tout plein

De pleurs, voyez quelle enflure

M'a fait une égratignure!"

Alors Vénus se sourit

Et en le baisant le prit,

Puis sa main lui a soufflée

Pour guérir sa plaie enflée.

"Qui t'a, dis-moi, faux garçon, Blessé de telle façon?

Sont-ce mes Grâces riantes,

De leurs aiguilles poignantes?

- Nenni, c'est un serpenteau,

Qui vole au printemps nouveau Avecques deux ailerettes

Ça et là sur les fleurettes. 
- Ah ! vraiment je le connois,

Dit Vénus; les villageois

De la montagne d'Hymette

Le surnomment Mélissette.

Si doncques un animal

Si petit fait tant de mal,

Quand son alène époinçonne

La main de quelque personne,

Combien fais-tu de douleur, Au prix de lui, dans le coeur

De celui en qui tu jettes

Tes amoureuses sagettes ?

Ronsard, Odes, 16, livre IV, 1550. 